\title{
ANALISIS VEGETASI DALAM UPAYA PENGEMBANGAN WISATA DI TAMAN WISATA ALAM PUNTI KAYU PALEMBANG PROVINSI SUMATERA SELATAN
}

\author{
Akbar Rulianto', Afif Bintoro'), Gunardi Djoko Winarno'), Rahmat Safe'i'. \\ ${ }^{1)}$ Fakultas Pertanian, Universitas Lampung \\ Jl. Sumantri Brojonegoro No. 1 Bandar Lampung.
}

\begin{abstract}
Punti Kayu Natural Tourism Park is a conservation forest contained in Palembang with an area of 50 hectares. Conservation forest utilization as a natural tourism park has a fantastic tourism development potential. Considering this matter, it is necessary to research about vegetation analysis at Punti Kayu nature tourism park for tourism development at Punti Kayu Palembang. The purpose of this research is to know the composition and structure of tree vegetation at TWA Punti Kayu Palembang. The research was conducted from April to June 2017. The method used in this research is Simple Random Sampling with 63 plot total sample. The results of this study obtained 24 tree species consisting of 949 tree phases, 114 pole phases, 141 sappling phases, and 375 phases of seedlings. Tree phases was dominated by Pinus Spesies with total 750 trees (INP 212,65\%), in the pole phase, sapplings phase and seedling phase were dominated by Talok with total 25 poles (INP 57,96\%), 17 sapplings (INP 39.89\%) and 60 seedlings (INP 29.51\%), The level of diversity of tree species and seedlings included in the low category, the tree of 0.493 and the seedlings of 0.824 . One characteristic of good vegetation is the high level of species diversity. according to Kristinawanti et al (2013) good tree vegetation will have a positive impact on increasing tourist visits The results of this research can be used to support tourism in Punti Kayu Nature Tourism Park because it can be used as a reference to assess the management of Punti Kayu Nature Tourism Park.
\end{abstract}

Key words : Punti Kayu Nature Tourism Park, Analysis of Vegetation, Composition, Stucture

\section{PENDAHULUAN}

Taman Wisata Alam Punti Kayu merupakan hutan konservasidi kota Palembang yang ditetapkan melalui SK Menhut No.9273/Kpts-II/2002 dengan luas 50 ha. Pemanfaatan hutan konservasi sebagai TWA memiliki potensi pengembangan wisata yang sangat tinggi. Tetapi fungsi TWA Punti Kayu sebagai taman wisata alam belumlah maksimal dikarenakan penurunan angka kunjungan dari tahun 2015 sampai dengan tahun 2017. Memperhatikan hal tersebut maka perlu dilakukan kajian tentang analisis vegetasi di TWA Punti Kayu Palembang untuk pengembangan pariwisata di Punti Kayu Palembang. Penelitian ini bertujuan untuk mengetahui komposisi, dan struktur vegetasi di dikawasan TWA Punti Kayu yang berguna sebagai bahan masukan / pertimbangan untuk pengembangan pariwisata yang ada di Punti Kayu Palembang.

\section{METODE PENELITIAN}

Penelitian dilakukan pada bulan April hingga Juni 2017 bertempat di TWA Punti Kayu Palembang provinsi Sumatera Selatan. Objek dalampenelitian ini adalah pohon pada semua fase pertumbuhan pohonpada kawasan TWA Punti Kayu Kota Palembang. Sedangkan alat yang digunakan dalam penelitian ini yaitu tali rafia untuk pembuatan plot, rol meter untukmengukur luas plot, pita meter dengan ketelitian 1 milimeter untuk mengukur diameter, hagameter yang digunakan untuk mengukur tinggi pohon, tally sheet, kuisioner, Smartphone dan Global Positioning System (GPS). Data yang dikumpulkan meliputi data primer dan data sekunder. Data primer diperoleh dari hasil pengamatan di lapangan meliputi jenis tumbuhan, jumlah spesies ,diameter dan tinggi (Erwin, 2016) sedangkan data sekunder diperoleh melalui studi pustaka dan informasi dari dinas terkait meliputi keadaan umum 
lokasi penelitian, Penelitian ini diawali dengan melakukan studi pendahuluan di TWA Punti Kayu Palembang, melakukan inventarisasi dan pendataan dimensi pohon, mengambil gambar/citra satelit kawasan TWA Punti Kayu Palembang, melakukan tabulasi dan analisis data hasil penelitian. Metode yang digunakan dalam menganalisis vegetasi TWA Punti Kayu. adalah metode Simple Random Sampling dengan Intensistas Sampling 5\% dan menggunakan plot berukuran $20 \mathrm{~m} \times 20$ m. Adapun desain dari plot yang diapakai dalam penelitian ini adalah sebagai berikut

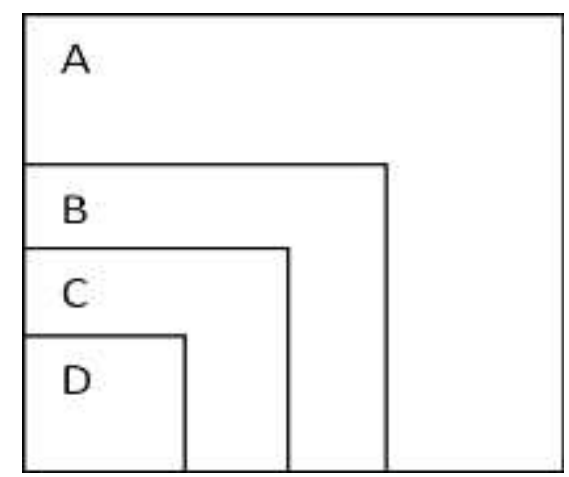

Gambar. 1 Desain Plot Penelitian

Diketahui plot A berukuran $20 \mathrm{~m} \times 20 \mathrm{~m}$ digunakan untuk pengukuran spesies fase pohon. Plot $B$ berukuran $10 \mathrm{~m} \times 10 \mathrm{~m}$ digunakan untuk pengukuran spesies fase tiang. Plot $\mathrm{C}$ berukuran $5 \mathrm{~m} \times 5 \mathrm{~m}$ digunakan untuk pengukuran spesies fase pancang dan Plot D berukuran $2 \mathrm{~m} \times 2 \mathrm{~m}$ digunakan untuk pengukuran spesies fase semai. Penentuan jumlah plot yang dipakai dalam penelitin ini diketahui melalui hasil dari perhitungan luas seluruh plot yang diamati dibagi luas petak ukur. Luas seluruh plot penelitian adalah 2,5 hektar dan luas petak ukur adalah 0,04 hektar. Dari perhitungan tersebut diketahui jumlah seluruh plot penelitian adalah 63 plot. Indeks Nilai Penting dihitung berdasarkan penjumlahan nilai Kerapatan Relatif (KR), Frekuensi Relatif (FR) dan Dominansi Relatif (DR), (Soerianegara dan Indrawan, 2005). Besarnya INP pada suatu vegetasi dapat dihitung dengan persamaan berikut:

$$
\begin{aligned}
& \text { Kerapatan }(\mathrm{K})=\frac{\text { Jumlah individu suatu jenis }}{\text { luas seluruh petak contoh }} \\
& \text { K. Relatif }(\mathrm{KR})=\frac{\text { K. suatu jenis }}{\text { K. seluruh jenis }} \times 100 \% \\
& \text { Frekuensi }(\mathrm{F})=\frac{\text { Jml plot dtmukan suatu jenis }}{\text { Jml seluruh petak }} \\
& \text { Frekuensi }(\mathrm{F})=\frac{\text { Jml plot dtmukan suatu jenis }}{\text { Jml seluruh petak }} \\
& \text { F. Relatif }(\mathrm{FR})=\frac{\text { F. suatu jenis }}{\text { F. seluruh jenis }} \times 100 \% \\
& \text { Dominansi (D) }=\frac{\text { L. basal area suatu spesies }}{\text { L. seluruh petak contoh }} \\
& \text { D. Relatif (DR) }=\frac{\text { D. suatu jenis }}{\text { D. seluruh jenis }} x 100 \%
\end{aligned}
$$

(Indriyanto, 2006)

Berdasarkan persamaan tersebut, maka untuk menghitung besar Indeks Nilai Penting (INP) pada suatu spesies untuk fase pancang, tiang dan pohon menggunakan rumus (Indriyanto, 2006) :

$$
I N P=K R+F R+D R
$$

Sedangkan untuk menghitung INP pada fase semai menggunakan rumus Mueller Dombois dan Ellenberg, (1974) dalam Ernawati (2013) :

$$
I N P=K R+F R
$$

Cara menghitung indeks keanekaragaman $\left(\mathrm{H}^{\prime}\right)$ menggunakan rumus indeks keanekaragaman Shanon-Wienner(Maguran, 1988).

$$
\mathrm{H}^{\prime}=\sum_{\mathrm{i}=1}^{\mathrm{s}} \cdot(\mathrm{pi})(\ln \mathrm{pi})
$$

Keterangan :

$$
\begin{aligned}
& \mathrm{H}^{\prime}=\text { Indeks Keragaman Shannon- } \\
& \mathrm{Pi}=\text { Jumlah individu suatu spesies } \\
& \mathrm{Ni}=\text { Jumlah individu spesies ke-i } \\
& \mathrm{N}=\text { Jumlah total individu }
\end{aligned}
$$

dengan kriteria :

$$
\begin{array}{ll}
H^{\prime}<1 & =\text { Rendah } \\
1<H^{\prime} \leq 3 & =\text { Sedang } \\
\mathrm{H}<3 & =\text { Tinggi }
\end{array}
$$


Selanjutnya untuk menghitung indeks kekayaanl jenis $(R)$ menggunakan rumus indeks kekayaan Jenis Margalef (1958) :

$$
\mathrm{R}=\frac{S-1}{\operatorname{Ln}(\mathrm{N})}
$$

dimana:

$\mathrm{R}=$ indeks kekayaan jenis

$\mathrm{S}=$ jumlah total jenis dalam suatu habitat

$\mathrm{N}=$ jumlah total individu dalam suatu habitat

dengan kriteria :

$$
\begin{array}{ll}
\mathrm{R}<2,5 & =\text { Rendah } \\
2,5>\mathrm{R}>4 & =\text { Sedang } \\
\mathrm{R}>4 & =\text { Tinggi }
\end{array}
$$

\section{HASIL PENELITIAN}

\section{A. Komposisi dan Struktur Vegetasi}

Berdasarkan hasil penelitian ditemukan sebanyak 24 spesies dan 18 famili pohon dengan jumlah 1580 pohon sebagai komposisi vegetasi yang ada di TWA Punti Kayu. Pohon terdiri dari berbagai macam fase yaitu fase semai ase pancang, fase tiang dan fase pohon. Pada fase semai terdapat 375 semai, pada fase pancang terdapat 141 pancang, pada fase tiang terdapat 114 tiang dan pada fase pohon terdapat 949 pohon. Komposisi jenis adalah susunan vegetasi dari setiap tingkatan pertumbuhan mulai terkecil atau dapat juga dikatakan sebagai kekayaan floristic pada lingkungan tertentu (Mueller dan Ellenberg 1974). Komposisi jenis pohon pada suatu areal hutan dapat diketahui dengan melakukan perhitungan terhadap beberapa parameter yang meliputi Indeks Nilai Penting (INP). Jenis dominan pada setiap tingkat fase pohon di TWA Punti Kayu Palembang dapat dilihat pada Tabel 1.

Berdasarkan Tabel 1. dapat diketahui bahwa pada tingkat fase semai didominasi oleh species Talok (Microcos tomentosa) dengan INP 29,51\%. Pada tingkat fase pancang didominasi oleh species Talok (Microcos tomentosa) dengan INP 39,89\%. Pada Tingkat Fase Tiang didominasi oleh species talok dengan INP 57,96\%. Pada Tingkat Fase Pohon didominasi oleh species pinus (Pinus mer kusii) dengan INP 212,56 \%. Species Talok (Microcos tomentosa) mendominasi tiga tingkat fase pertumbuhan pohon, sedangkan tingkat fase pohon didominasi oleh species. Pinus (Pinus merkusii). Hal ini diduga karena species Talok (Microcos tomentosa) memiliki pertumbuhan yang cepat, daya adaptasi yang baik dan tidak perlu perlakuan khusus untuk melakukan persemaian ( persemaian terjadi secara alami ). Sedangkan untuk species lainnya tidak memiliki pertumbuhan dan daya adaptasi sebaik spesiesTalok, serta dalam menyemaikanya memerlukan perlakuan khusus, sehingga spesies lainya kalah bersaing dengan species Talok. Menurut Tjitrosoedirjo (2007) keberadaan tumbuhan asing invasif dapat mengintervensi habitat alami dan mengancam keberadaaan jenis tumbuhan asli. Pada spesies Pinus (Pinus merkusii) tidak terdapat tumbuhan pada tingkat fase semai, hal ini disebabkan oleh berbagai faktor salah satunya topografi. Menurut Amalia (2013), tanaman pinus dapat hidup optimal pada suhu tahunan berkisar dari 19 sampai $28{ }^{\circ} \mathrm{C}$ dan pada ketinggian 200 sampai $1700 \mathrm{~m}$ dpl. Sedangkan di TWA Punti Kayu memiliki ketinggian 3-20 mdpl dengan temperatur 28ㅇ - 34으 C. JadiTWA Punti Kayu tidak memenuhi kriteria topografi optimal untuk pertumbuhan tanaman pinus, sehingga tidak ditemukan fase semai pada spesies tanaman pinus. Berdasarkan penelitian terdahulu yang dilakukan Syabana dkk (2013) TWA Punti Kayu didominasi oleh Pinus (Pinus merkusii), meskipun tidak ditemukannya permudaan dari Pinus (Pinus merkusi) karena kondisi tapak yang tidak sesuai.Struktur vegetasi merupakan penampakan susunan tegakan berdasarkan sebaran diameter, tingkat permudaan pancang, tiang dan pohon, lapisan tajuk dan penyebaran dalam ruang (Indriyanto, 2006). Berdasarkan data tersebut diketahui bahwa struktur vegetasi di TWA Punti Kayu didominasi oleh fase pohon. Hal disebabkan karena berdasarkan data yang didapat dari BKSDA Sumsel (2015), kawasan TWA Punti Kayu merupakan bekas lahan uji coba pertanaman pinus pada jaman kolonial Belanda sejak tahun 1937, sehingga kawasan ini didomiasi oleh fase 
Tabel1. Sepuluh jenis species dominan pada tiap tingkat fase pohon berdasarkan perhitungan Indeks Nilai Penting di TWA Punti Kayu Palembang.

\begin{tabular}{|c|c|c|c|c|c|}
\hline Nama Jenis & Jumlah Individu & K (indv/Ha) & $\mathbf{F}$ & $\mathrm{D}(\mathrm{m} 2 / \mathrm{Ha})$ & INP \\
\hline \multicolumn{6}{|l|}{ Semai } \\
\hline Talok & 60 & 24 & 0,24 & 0,05 & $29,51 \%$ \\
\hline Akasia & 55 & 22 & 0,22 & 0,03 & $27,28 \%$ \\
\hline Angsana & 45 & 18 & 0,22 & 0,04 & $24,61 \%$ \\
\hline Mahoni & 28 & 11,2 & 0,11 & 0,02 & $13,78 \%$ \\
\hline Kanigara & 20 & 8 & 0,1 & 0,01 & $10,74 \%$ \\
\hline Jarak & 17 & 6,8 & 0,05 & 0,02 & $7,23 \%$ \\
\hline Jati putih & 17 & 6,8 & 0,1 & 0,01 & $9,94 \%$ \\
\hline Sonokeling & 17 & 6,8 & 0,08 & 0,02 & $9,03 \%$ \\
\hline Bungur & 15 & 6 & 0,08 & 0,01 & $8,50 \%$ \\
\hline Damar & 15 & 6 & 0,1 & 0,01 & $9,41 \%$ \\
\hline \multicolumn{6}{|l|}{ Pancang } \\
\hline Talok & 17 & 6,8 & 0,11 & 0,03 & $39,89 \%$ \\
\hline Ketapang & 15 & 6 & 0,11 & 0,02 & $35,15 \%$ \\
\hline Angsana & 15 & 6 & 0,1 & 0,02 & $32,37 \%$ \\
\hline Jambu air & 15 & 6 & 0,08 & 0,02 & $29,27 \%$ \\
\hline Jarak & 13 & 5,2 & 0,06 & 0,02 & $26,50 \%$ \\
\hline Jati putih & 12 & 4,8 & 0,08 & 0,02 & $28,00 \%$ \\
\hline Salam & 10 & 4 & 0,1 & 0,01 & $23,83 \%$ \\
\hline $\begin{array}{l}\text { Rambutan } \\
\text { Kanigara }\end{array}$ & $\begin{array}{l}10 \\
10\end{array}$ & $\begin{array}{l}4 \\
4\end{array}$ & $\begin{array}{l}0,06 \\
0,06\end{array}$ & $\begin{array}{l}0,01 \\
0,01\end{array}$ & $\begin{array}{l}19,39 \% \\
16,72 \%\end{array}$ \\
\hline Mahoni & 6 & 2,4 & 0,03 & 0,01 & $12,49 \%$ \\
\hline \multicolumn{6}{|l|}{ Tiang } \\
\hline Talok & 25 & 10 & 0,11 & 0,18 & $57,96 \%$ \\
\hline Akasia & 20 & 8 & 0,08 & 0,11 & $45,19 \%$ \\
\hline Ketapang & 17 & 6,8 & 0,08 & 0,16 & $47,91 \%$ \\
\hline Kanigara & 15 & 6 & 0,1 & 0,06 & $36,23 \%$ \\
\hline $\begin{array}{l}\text { Angsana } \\
\text { Marpoyan }\end{array}$ & $\begin{array}{c}12 \\
7\end{array}$ & $\begin{array}{l}4,8 \\
2,8\end{array}$ & $\begin{array}{l}0,06 \\
0,05\end{array}$ & $\begin{array}{l}0,07 \\
0,06\end{array}$ & $\begin{array}{l}29,31 \% \\
21,62 \%\end{array}$ \\
\hline Mahoni & 5 & 2 & 0,03 & 0,04 & $14,08 \%$ \\
\hline Bungur & 4 & 1,6 & 0,03 & 0,04 & $13,37 \%$ \\
\hline Pulai & 3 & 1,2 & 0,03 & 0,02 & $10,16 \%$ \\
\hline Jengkol & 2 & 0,8 & 0,02 & 0,02 & $7,14 \%$ \\
\hline \multicolumn{6}{|l|}{ Pohon } \\
\hline Pinus & 750 & 300 & 1 & 73,84 & $212,56 \%$ \\
\hline Talok & 46 & 18,4 & 0,24 & 2,16 & $18,36 \%$ \\
\hline Akasia & 25 & 10 & 0,11 & 0,76 & $8,65 \%$ \\
\hline Ketapang & 17 & 6,8 & 0,1 & 0,81 & $7,13 \%$ \\
\hline Medang kuning & 15 & 6 & 0,1 & 0,84 & $6,96 \%$ \\
\hline Talok & 60 & 24 & 0,24 & 0,05 & $29,51 \%$ \\
\hline Akasia & 55 & 22 & 0,22 & 0,03 & $27,28 \%$ \\
\hline Angsana & 45 & 18 & 0,22 & 0,04 & $24,61 \%$ \\
\hline Mahoni & 28 & 11,2 & 0,11 & 0,02 & $13,78 \%$ \\
\hline Kanigara & 20 & 8 & 0,1 & 0,01 & $10,74 \%$ \\
\hline Jarak & 17 & 6,8 & 0,05 & 0,02 & $7,23 \%$ \\
\hline
\end{tabular}

(Sumber: Hasil Penelitian Tahun 2017). 
pohon spesies pinus. Hal ini sesuai dengan penelitian yang dilakukan oleh Syabana dkk (2013) struktur vegetasi kawasan TWA Punti Kayu didominasi oleh struktur vegetasi tingkat pohon. Hal ini dapat dilihat pada gambar 1 .

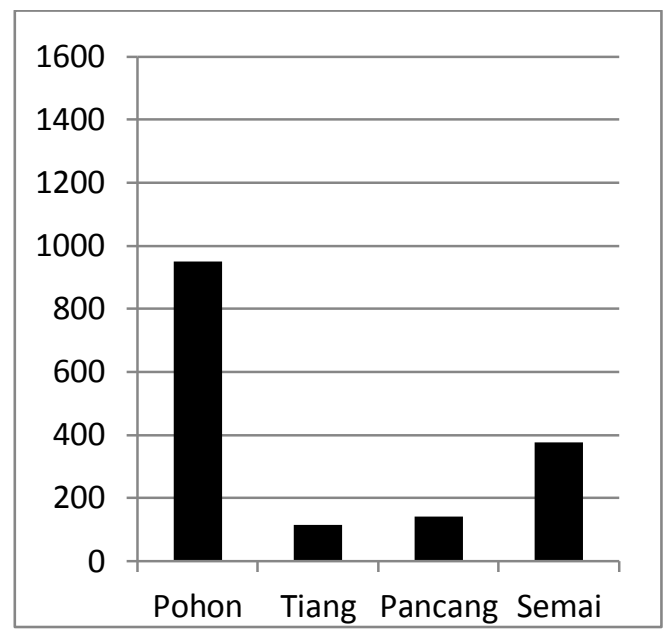

Gambar 1. Perbandingan Jumlah SpesiesTiap Fase Pohon.

\section{B. Indeks Keanekaragaman (H')}

Nilai indeks keanekaragaman jenis dapat digunakan untuk mengetahui pengaruh gangguan terhadap lingkungan atau untuk mengetahui tahapan suksesi dan kestabilan dari komunitas tumbuhan pada suatu lokasi (Odum, 1996).Berdasarkan hasil peneitian yang dilakukan, diketahui bahwa Indeks Keanekaragaman Species pada fase semai dan pohon di TWA Punti Kayu tergolong rendah. Hal ini sesuai dengan penelitian yang dilakukan oleh Syabana dkk (2013), bahwa TWA Punti Kayu memiliki Indeks Keanekaragaman fase semai dan pohon yang rendah. Pada fase tiang dan pancang indeks keanekaragaman dikategori sedang. Hal ini dapat dilihat pada tabel 2.

Tabel 2. Indeks Keanekaragaman Spesies TWA Punti Kayu Palembang

\begin{tabular}{lll}
\hline Fase Pertumbuhan & H' & Kategori \\
\hline Semai & 0,824 & Rendah \\
Pancang & 1,186 & Sedang \\
Tiang & 1,372 & Sedang \\
Pohon & 0,493 & Rendah \\
\hline
\end{tabular}

(Sumber: Hasil Penelitian Tahun 2017).
TWA Punti Kayu didominasi oleh Pinus (Pinus merkusii) sehingga menyebabkan tingginya penutupan tajuk sehingga menyebabkan keanekaragaman jenis rendah. Jika tidak dilakukan penanaman kembali maka spesies Pinus (Pinus merkusii) di TWA Punti Kayu akan punah dan tergantikan dengan spesies baru yang memiliki pertumbuhan cepat dan adaptasinya baik. Magurran(1988) dalam Maknun (2014) menjelaskan bahwa nilai indeks keanekaragaman $\left(\mathrm{H}^{\prime}\right)$ berhubungan dengan kekayaan spesies pada lokasi tertentu, tetapi juga dipengaruhi oleh distribusi kelimpahan spesies. Semakin tinggi nilai indeks $\mathrm{H}^{\prime}$ maka semakin tinggi pulakeaneka-ragaman spesies, produktivitas ekosistem, tekanan pada ekosistem dan kestabilan ekosistem.

\section{Indeks Kekayaan (R)}

Indeks Kekayaan jenis adalah jumlah jenis (spesies) dalam suatu komunitas. Semakin banyak jumlah jenis yang ditemukan maka indeks kekayaannya juga semakin besar. Perhitungan indeks kekayaan menggunakan rumus indeks kekayaan jenis Maragalef (1958) dalam Ismawan (2015). Berdasarkan perhitungan indeks kekayaan diketahui bahwa vegetasi TWA Punti Kayu Palembang memiliki Indeks Kekayaan yang tinggi. Hal ini disajikan pada tabel 4.

Tabel 4. Indeks Kekayaan Spesies TWA Punti Kayu Palembang

\begin{tabular}{ccc}
\hline $\begin{array}{c}\text { Fase } \\
\text { Pertumbuhan }\end{array}$ & $\mathbf{R}$ & Kategori \\
\hline Semai & 21,83 & Tinggi \\
Pancang & 15,80 & Tinggi \\
Tiang & 13,79 & Tinggi \\
Pohon & 19,85 & Tinggi \\
\hline
\end{tabular}

(Sumber: Hasil Penelitian Tahun 2017)

Berdasarkan Tabel 4 diketahui bahwa vegetasi TWA Punti Kayu Palembang memiliki Indeks Kekayaan yang tinggi. Hal ini dikarenakan status TWA Punti Kayu digolongkan sebagai hutan konservasi sehingga vegetasinya tidak boleh diganggu. Indeks kekayaan Margalef 
membagi jumlah spesies dengan fungsi logaritma natural yang mengindikasikan bahwa pertambahan jumlah spesies berbanding terbalik dengan pertambahan jumlah individu Hal ini juga menunjukkan bahwa biasanya pada suatu komunitas/ekosistem yang memiliki banyak spesies akan memiliki sedikit jumlah individunya pada setiap spesies tersebut (Ismaini dkk, 2015).

\section{Hubungan Analisis Vegetasi Dengan Pengembangan Wisata}

Pengelolaan TWA Punti Kayu selama ini ditangani oleh pihak lembaga /instansi pemerintah, swasta maupun masyarakat, baik dari tingkat daerah / propinsi maupun Unit Pelaksana Teknis ( UPT ) pusat di daerah. Akan tetapi pelaksanaan program penangannya selama ini belum terkoordinasi dengan baik, masing-masing tingkatan pemerintahan melaksanakan kegiatan masih terpilah-pilah dengan menonjolkan ego sektoral. Seperti halnya serangkaian pelaksanaan program rehabilitasi hutan dan lahan dilakukan oleh Balai Pengelolaan Daerah Aliran Sungai dan Hutan Lindung (BPDASHL Musi) bersama-sama dengan Dinas Kehutanan Propinsi Sumatera Selatan atau studi dan pengamanan dilakukan oleh Balai Konservasi Sumber Daya Alam (BKSDA) Sumatera Selatan, dan Penelitian dilakukan oleh Balai Litbang LHK Palembang sehingga bentuk penanganannya belum menampakkan keberhasilan yang signifikan hal ini disebabkan oleh karena perencanaan dan konsep penanganannya belum berdasarkan pada perencanaan yang terintegrasi. Berkaitan dengan peran dan fungsi Taman Wisata Alam Punti Kayu,beradasarkan data pengunjung pada tahun 2015-2017, ternyata TWA Punti Kayu Palembang masih belum sesuai dengan tujuan utama sebagai taman wisata alam. Diketahui angka kunjungan wisata TWA Punti Kayu mengalami penurunan dari tahun 2015 sampai dengan tahun 2017. Hal ini disebabkan oleh berbagai faktor,seperti keadaan vegetasi TWA Punti Kayu .Berdasarkan hasil dari analisis vegetasi di TWA Palembang, indeks keaneka-ragaman pohon pada tingkat fase semai dan pohon di TWA Punti Kayu tergolong rendah. Untuk meningkatan kesejukan dan keane-karagaman flora di TWA Punti Kayu, adapun solusi yang ditawarkan adalah dengan melakukan penanaman pohon yang dapat menunjang kegiatan wisata dan memiliki nilai estetika. menurut Santoso (2013) adalah Angsana (Pterocarpus indicus), Filicium (Filicium decipiends), Ketapang (Terminalia catappa), Beringin (Ficus benjamina), Kupu-kupu (Bauhinia tomentosa), Puspa (Schima wallichii), dan Kenari (Canarium ovatum).

Pengembangan wisata alam tidak hanya mempertemukan kepentingan konservasi dan pariwisata , namun terutama untuk mengurangi tekanan terhadap kawasan yang pada gilirannya akan diperoleh pemanfaatan sumber daya alam hayati dan ekosistemnya secara lestari (Kristinawanti dkk, 2013). Pengembangan suatu kawasan pariwisata alam yang lestari dan berkelanjutan memerlukan kesinergian antara multistakeholder serta Strategi Pengembangan Pariwisata Alam di TWA untuk menuju pengelolaan kawasan potensial yang baik, oleh karena itu diperlukan konservasi taman wisata alam yang efektif (Oktadiyani dkk, 2015). Jika hutan mengalami kerusakan, maka sumber daya yang ada akan menghilang. Hilangnya sumber daya yang dimanfaatkan untuk wisata tersebut akan mengurangi minat para wisatawan untuk berkunjung, sehingga akan berdampak pada pemasukan bagi pendapatan pemerintah. Dengan demikian, vegetasi pohon yang baik akan berdampak positif pada peningkatan kunjungan wisata (Kristinawanti dkk., 2013).

\section{KESIMPULAN DAN SARAN}

\section{A. Kesimpulan}

Berdasarkan hasil penelitian yang telah dilakukan, dapat diperoleh kesimpulan sebagai berikut :

1. Fase semai, pancang, dan tiang di dominasi oleh Spesies Talok (Micrococos tomentosa) Sedangkan fase pertumbuhan tingkat pohon 
13 / Rulianto, A., A. Bintoro, G. D. Winarno, R. Safe'i

didominasi oleh species Pinus (Pinus merkusii).

2. TWA Punti Kayu memiliki tingkat keanekaragaman yang rendah pada fase pohon dan semai, sedangkan pada fase pancang dan tiang memiliki tingkat keanekaragaman yang sedang.

3. Indeks kekayaan spesies di TWA Punti Kayu tergolong tinggi.

\section{B. Saran}

Saran yang dapat diberikan adalah sebagai berikut :

1. Perlu adanya pengayaan jenis pohon yang dapat berfungsi sebagai peneduh dan penunjang estetika seperti Beringin, Ketapang ,Kenari dan lainlain.

2. Diperlukan evaluasi fasilitas untuk menunjang kegiatan wisata yang ada di TWA Punti Kayu.

3. Meningkatkan kerjasama antar pihak (Stakeholder) dalam rangka pengelolaan TWA Punti Kayu.

\section{DAFTAR PUSTAKA}

Balai Konservasi Sumber Daya Alam (BKSDA) Sumatera Selatan.2003. Rencana Pengelolaan Taman Wisata Alam Punti Kayu Periode tahun 2004 -2028. Tidak dipublikasikan. Palembang.

Balai Konservasi Sumber Daya Alam (BKSDA) Sumatera Selatan.2015. Rekap Data Pengungjung Taman Wisata Alam Punti Kayu 2015-2017. Tidak dipublikasikan. Palembang

Ernawati. 2013. Komposisi Jenis dan Penguasaan Ekologi di Wilayah Desa Pangi Kawasan Cagar Alam Pangi Binangga Kabupaten Parigi Moutong. J. Warta Rimba. 1 : 1-9.

Erwin. 2016. Komposisi Struktur Vegetasi Di Blok Pemanfaatan Hutan Pendidikan Konservasi Terpadu (HPKT) Taman Hutan Raya Wan Abdul Rahman. J. Sylva Lestari. 5(3) : 1-11.
Indriyanto. 2006. Ekologi Hutan. PT Bumi Aksara. Jakarta. 198p.

Ismaini, L. , Lailati, M. , Rustandi dan Dadang, S. 2015. Analisis Komposisi dan Keanekaragaman Tumbuhan di Gunung Dempo, Sumatera Selatan. J. Pros Sem Nas MASY Biodiv Indon. 1 : 1397 - 1402.

Ismawan, A. Sofia, E. R. Dan A. Dhamrmawan. 2015.Kelimpahan dan Keanekaragaman Burung di Prevab Taman Nasional Kalimantan Timur.. J. Universitas Malang. 1:9.

Magurran, A.E. 1988. Ecological Diversity and Its Measurement. USA.Chapman and Hall.192p.

Maknun, I. 2014. Pemanfaatan Hijauan di Lahan Irigasi di Desa Cihedeung Udik, Cibitung Tengah, Dan Situ Udik, Kabupaten Bogor, Jawa Barat. J. Seminar Nasional Kebangkitan Perternakan II. 1: 404-412.

Odum, E . P. 1972. Fundamentals of Ecology. London - Toronto .W. B. Saunder Company Philadelphia. $546 p$.

Oktadiyani, P., Iwanuddin dan Helwinsyah. 2015. Strategi Pengembangan Pariwisata Alam Taman Wisata Alam Wera. J. Wasian. 2 : 919.

Santoso, S. , Sri, L. dan Samiyarsih, S. 2013. Inventarisasi Tanaman Peneduh Jalan Penjerap Timbal di Purwokerto. Jurnal. 1 : 197-202.

Soerianegara, I. dan Indrawan. 2005. Ekologi Hutan Indonesia. Bogor: Fakultas Kehutanan, Institut Pertanian Bogor. 83p.

Syabana, T.A. A., Mareti, S dan Kunarso, A. 2015.Cadangan Karbon pada Tegakan Tingkat Tiang dan Pohon di Taman Wisata Alam Punti Kayu Palembang. J. Prosiding Seminar Nasional MAPEKI XVIII. 423-430. 
Tjitrosoedirdjo, S.S. 2011. Identifikasi

Asystasia gangetica (L.) T. Aderson subsp. Micrantha (Nees) Ensermu. J.
Gulma dan Tumbuhan Invasif Tropika 2(1):39 -40 